\title{
The Impact of Preoperative Nutritional Status of Elderly Patients on the Postoperative Outcome: Comparison of Two Nutritional Assessment Tests and Biochemical Tools
}

\author{
Özlem Sezen (1), Banu Çevik (1)
}

Department of Anesthesiology and Reanimation, University of Health Sciences, Kartal Dr. Lütfi Kırdar Training and Research Hospital, İstanbul, Turkey

ORCID iDs of the authors: Ö.S. 0000-0002-2|44-9224; B.C̣. 0000-0002-7872-1794.

Cite this article as: Sezen Ö, Çevik B. The Impact of Preoperative Nutritional Status of Elderly Patients on the Postoperative Outcome: Comparison of Two Nutritional Assessment Tests and Biochemical Tools. Cyprus J Med Sci 2020; 5(4): 333-8.

\section{BACKGROUND/AIMS}

Our main goal was to compare the two validated nutritional screening tools and serum proteins that are used as routine biochemical markers for the prediction of the postoperative outcome.

\section{MATERIAL and METHODS}

The current study was design to evaluate the prevalence of malnutrition among elderly patients undergoing elective curative gastrointestinal cancer and trochanteric hip fracture surgery. On admission to the preoperative holding area, all patients underwent the two nutritional screening tests: Mini Nutritional Assessment (MNA) and Nutritional Risk Screening 2002 (NRS - 2002). After assessment, all participants were followed-up throughout their hospital stay. We calculated the lymphocyte-monocyte ratio (LMR) and albumin-globulin ratio (AGR) according to the laboratory results. The surgical outcome (discharge to ward/intensive care) and postoperative infection (systemic or surgical site) were recorded.

\section{RESULTS}

The group of patients with MNA < 17 (malnutrition) had a significantly high ICU admission rate and incidence of systemic or surgical infection, which led to the prolonged length of hospital stay. According to the NRS-2002 screening tool, the ICU admission rate was higher in patients with a score $\geq 3$. The surgical site infection rate in this group was also significantly higher than that of the patients with an NRS-2002 score $<3$. When comparing the two screening tools, the incidence of ICU admission was significantly higher in patients with MNA $>$ 17. The mean serum albumin and globulin levels and the AGR was comparable between before and after the surgery. However, the mean LMR was significantly lower than the preoperative value.

\section{CONCLUSION}

Measurements with easy-to-perform tests will provide guidance in terms of identifying potential perioperative risks.

Keywords: Malnutrition, older adults, nutritional biomarkers, MNA, NRS-2002

\section{INTRODUCTION}

People are living longer worldwide, and the proportion of the population that is over 60 years is expected to increase from $12 \%$ to $22 \%$ between 2015 and 2050 (I). With increasing age, people have various age-related co-morbidities, and many of them require hospitalization. A larger proportion of the elderly population undergoes surgical procedures due to advances in surgical, anesthetic, and intensive care interventions.

Malnutrition leads to a progressive decline in the health condition, reduced physical and cognitive functional status, increased utilization of health care services, premature institutionalization, and increased mortality in the elderly population (2).

Determining the malnutrition risk is an important area of concern, and precautions need to be taken in order to initiate appropriate nutritional support. However, physicians do not always have enough time to treat malnutrition. Due to functional alterations caused by malnutrition, falls are frequent in the geriatric population, and hip fracture is 
one of the main reasons of hospitalization. Early hip surgery within 48 hours was recommended because of the decrease in mortality risk and perioperative complications (3). A recent meta-analysis indicated that the prevalence of malnutrition in patients with hip fracture was approximately $18.7 \%$ using the Mini-Nutritional Assessment (MNA) test. Using the Body Mass Index (BMI) as a diagnostic tool, the prevalence increased up to $45.7 \%$ (4). Malignancies are the other main cause of malnutrition, and weight loss can sometimes be the first symptom of cancer. A systematic review revealed that malnutrition was significantly positively associated with increased risk of all-cause mortality (5). In a retrospective study that included 709 adult patients in 25 Brazilian hospitals, the incidence of complications among patients with malnutrition was $27 \%$ (relative risk $[R R]=1.60$ ) compared with $17 \%$ among the well-nourished counterparts. The mortality of patients with malnutrition and well nutrition was $12.4 \%$ vs $4.7 \%$, respectively $(R R=2.63)(6)$.

Nutritional assessment is a systemic process and can be done by using the $A B C D$ methods, that is, the anthropometry, biochemical/biophysical, clinical, and dietary methods (7). Although many screening and diagnostic tools have been introduced in clinical practice, no single test is sufficient for the assessment of the nutritional status (8). The Nutritional Risk Screening 2002 (NRS 2002) test and Mini Nutritional Assessment (MNA) are the most common screening tools for hospitalized patients (9, 10). The MNA is a more useful tool for the identification of frail patients (II).

Many nutritional assessments and screening tools use biochemical markers such as albumin, prealbumin, transferrin, C-reactive proteins, and total lymphocyte count. Albumin is mostly used as a laboratory marker to assess the nutritional status in daily clinical practice. However, its sensitivity and specificity is a controversial issue. A recent meta-analysis indicated that serum albumin level was strictly affected by the nutritional status and that hypovolemia is a negative prognostic index in the elderly population (12). Globulin is another major component of serum proteins that plays a role in the immune and chronic inflammatory process. Both serum levels of albumin and globulin alone could be easily affected by many factors; therefore, albumin-to-globulin ratio (AGR) was recommended as a valuable prognostic factor, especially in the cancer patients (I3).

The current study was design to evaluate the prevalence of malnutrition among elderly patients undergoing elective curative gastrointestinal cancer and trochanteric hip fracture surgery. The main goal was to compare the two validated nutritional screening tools and serum proteins that are used as routine biochemical markers for the prediction of the postoperative outcome.

\section{MATERIAL and METHODS}

This prospective, observational, cross-sectional study was conducted after receiving approval from the Institutional Ethics Committee (decision no:2018/5/4/144/3) according to the ethical principles outlined in the Helsinki Declaration and Good Clinical Practice guideline. Written informed consents were obtained from all the participants.

\section{Study Population}

We consecutively enrolled patients aged $\geq 65$ years who were scheduled for elective curative gastrointestinal cancer and trochanteric hip fracture surgery between January and April 2019.

\section{Exclusion Criteria}

Patients undergoing palliative or emergency surgery, aged $<65$ years, those who refused to participate in the study, having cognitive impairment, communication problems, multiple trauma patients, j and right-sided hip fractures were excluded.

\section{Assessment of the Nutritional Risk}

On admission to the preoperative holding area, all patients underwent the two nutritional screening tests; MNA and NRS2002. After assessment, all participants were followed-up throughout their hospital stay.

MNA has two forms, including the short (MNA-SF) and long form (MNA-LF). MNA-SF consists of six sections including appetite, recent weight loss, mobility impairment, acute illness, dementia or depression, and body mass index. We used the MNA-LF, which consisted of twelve more sections: Living arrangements, medications, presence of pressure ulcers, quality and number of meals, fluid intake, autonomy of feeding, self-perception about health and nutrition, and mid-upper arm and calf circumferences. Scores below 17 indicated malnourished, 17-23.5 at risk of malnutrition, and 24-30 normal nutritional status (14).

NRS-2002 consists of body mass index, weight loss, recent decrease in food intake and severity of illness. This tool has three components: a severity of disease score, a nutritional score, and an age score. The score ranges between 0 and 6 according to the assessment. We categorized the patients as well-medium risk $(<3)$ and nutritionally at risk $(\geq 3)(15)$.

\section{Anthropometric Measurements}

Personal characteristics such as age, gender, weight, height, and body mass index were recorded. Right middle arm circumference was measured at the mid-point between the acromial process of the scapula and the olecranon process of the ulna with the arm hanging loosely by the side. Calf circumference was measured from the widest part of the right leg while the patient was in the supine position and the knee was in a right angle between the thigh and calf.

\section{Laboratory Tests}

All laboratory data were acquired from patients within seven days prior to any surgery in our institution. In hip fractures, the laboratory tests depend on the admission date of the patients, and they are scheduled for surgery within three days. Total lymphocyte count, monocyte count, and serum albumin and globulin levels are part of the standard preoperative assessment laboratory tests for surgical patients.

\section{Data Collection}

For this study, clinical data were collected from the patient's electronic health records, including age, date of admission, clinical diagnosis, and American Society of Anesthesiologist' (ASA) physical status. All anthropometric measurements were performed by the same investigator. If the patient was unaware of his/her height, the investigator estimated the approximate 
height of the patient. In case of unknown body weight, we used the Buckley's bed side method for estimation of the body weight. This method uses the abdominal circumference (AC) and thigh circumference (TC) to estimate the actual body weight ( $A B W$ ) of the patient. In male and female patients, $\mathrm{ABW}$ is formulated as $-47.8+0.78 \times \mathrm{AC}+1.06 \times \mathrm{TC}$ and $-40.2+0.47 \times \mathrm{AC}+1.30 \times \mathrm{TC}$, respectively (16). The scores of MNA-LF and NRS-2002 were recorded. We retrieved the laboratory findings from the hospital electronic database and calculated the lymphocyte-monocyte ratio (LMR) and albumin-globulin ratio (AGR) according to the laboratory results. Surgical outcome (discharge to ward/intensive care) and the postoperative infection (systemic or surgical site) were recorded.

\section{Statistical Analysis}

Statistical analyses were performed using GraphPad Prism 8. While analyzing the study data, Student's t-test was used for comparisons between descriptive statistical parameters (mean, standard deviation, minimum and maximum value) and oneway ANOVA followed by the Tukey posttest for multiple comparisons.

The differences were considered statistically significant when $p$ values were $<0.05$ (*, $p<0.05 ;{ }^{* *}, p<0.01 ;{ }^{* * *}, p<0.001$ ). The data has been reported as mean \pm standard deviation (SD).

\section{RESULTS}

Totally, 100 patients were recruited into the study. We excluded 18 patients due to reoperation and missing data; therefore, statistical analysis was conducted using data from 82 patients (Figure I). Patients' characteristics and anthropometric measurements are shown in Table I. The mean serum albumin and globulin levels and the AGR were comparable between before and after operation. However, the mean LMR after surgery was significantly lower than the preoperative value (Table 2). The group of patients with MNA < 17 (malnutrition) had a significantly higher ICU admission rate and incidence of systemic or surgical infection, which led to the prolonged length of hospital stay (Table 3).

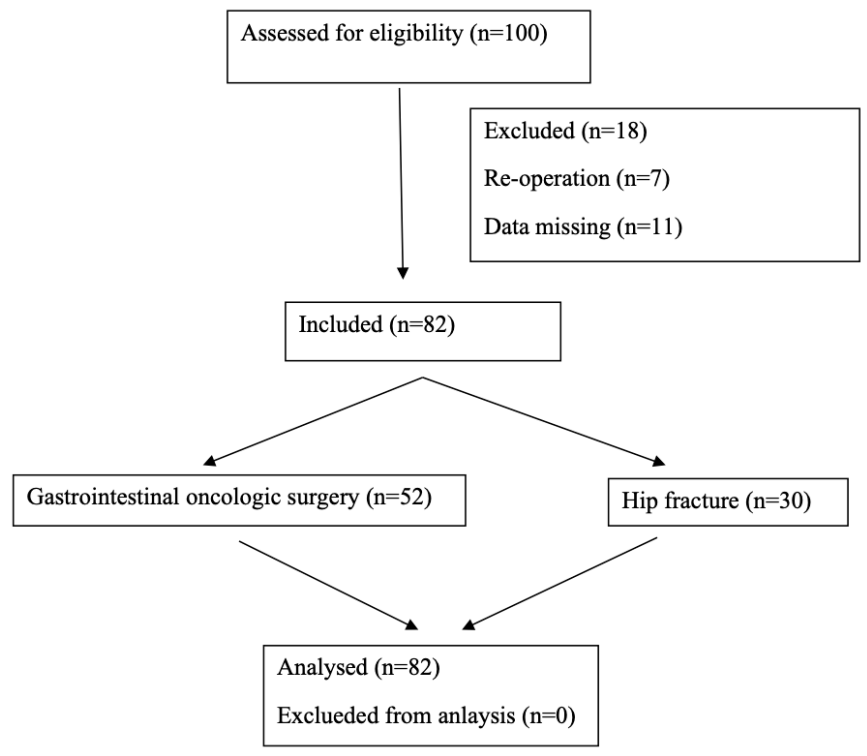

FIGURE I. The consort flowchart of the study
According to the NRS-2002 screening tool, the ICU admission rate was higher in patients with a score $\geq 3$. The incidence of surgical site infection in this group was also significantly higher than that of the patients with an NRS-2002 score < 3 (Table 4).

\begin{tabular}{|c|c|}
\hline Variables & Results \\
\hline Age (years)* & $73.57 \pm 8.25$ \\
\hline \multicolumn{2}{|l|}{ Gender ** } \\
\hline Female & $4 \mid(50)$ \\
\hline Male & $4 \mathrm{I}(50)$ \\
\hline Weight $(\mathrm{kg})^{*}$ & $67.70 \pm 11.24$ \\
\hline Height $(\mathrm{cm})^{*}$ & $163.7 \pm 8.97$ \\
\hline $\mathrm{BM}^{*}$ & $22.99 \pm 3.46$ \\
\hline \multicolumn{2}{|l|}{ ASA physical status** } \\
\hline II/III/IV & $50(60.98) / 29(35.37) / 3(3.65)$ \\
\hline Middle arm circumference $(\mathrm{cm})^{*}$ & $25.40 \pm 4.32$ \\
\hline Calf circumference $(\mathrm{cm})^{*}$ & $41.12 \pm 6.05$ \\
\hline
\end{tabular}

\section{TABLE 2. Patients' clinical data}

\section{Variables}

Results

Reason of admission'

GIS oncologic surgery

$52(63.41)$

Hip fracture

$30(36.59)$

Outcome'

Ward

48(58.54)

Intensive care unit

34(4l.46)

Length of hospital stay (days) ${ }^{2}$

$9.73 \pm 6.78$

Serum albumin level $(\mathrm{g} / \mathrm{dL})^{2}$

Preoperative

$3.22 \pm 0.56$

Postoperative

$2.76 \pm 0.52$

Serum globulin level $(\mathrm{g} / \mathrm{dL})^{2}$

Preoperative

$2.66 \pm 0.54$

Postoperative

$2.17 \pm 0.49$

$A G R^{2}$

Preoperative

$1.22 \pm 0.21$

Postoperative

$1.31 \pm 0.03$

Total lymphocyte count (\%) ${ }^{2}$

Preoperative

$15.44 \pm 8.57$

Postoperative

$8.85 \pm 5.16$

Monocyte count (\%)

Preoperative

$6.76 \pm 3.25$

Postoperative

$6.24 \pm 3.04$

LMR $^{2}$

$\begin{array}{ll}\text { Preoperative } & 2.52 \pm 1.53 \\ \text { Postoperative } & 1.56 \pm 1.01^{*}\end{array}$

GIS: Gastrointestinal system; AGR: Albumin-globulin ratio; LMR: Lymphocyte-monocyte ratio

Data was expressed as 'the number of patients ( $n$ ) and the percentage (\%)

and ${ }^{2}$ Mean \pm Standard Deviation (SD); ${ }^{*}$ highly significant. 
TABLE 3. The correlation of MNA groups with the study parametersl (Mean \pm SEM)

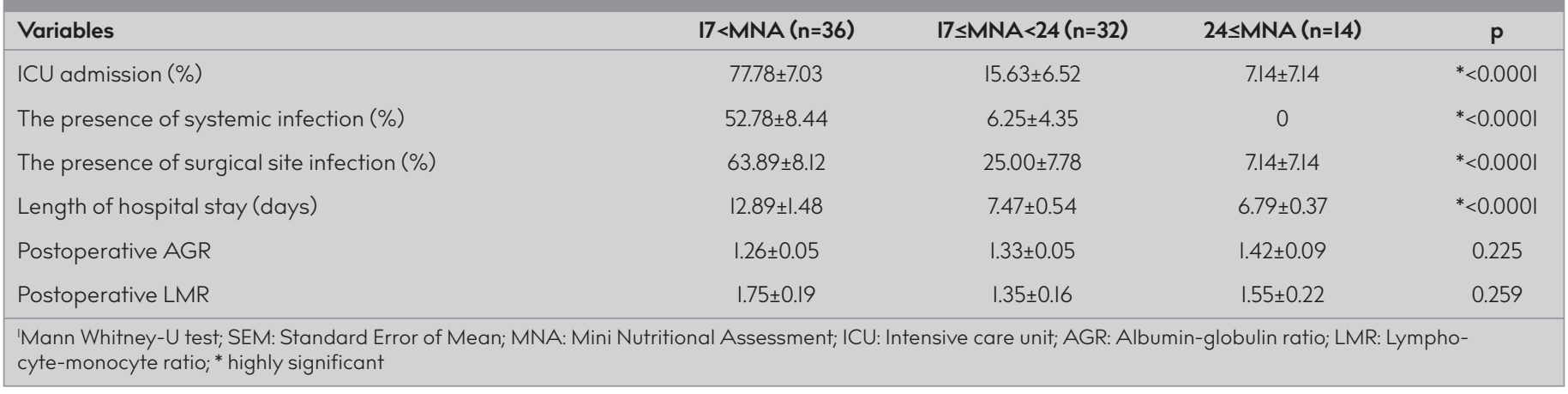

\begin{tabular}{|c|c|c|c|}
\hline Variables & $\begin{array}{c}\text { NRS }-2002<3 \\
\quad(n=15)\end{array}$ & $\begin{array}{l}\text { NRS-2002 } \\
\quad(n=67)\end{array}$ & $\mathbf{p}$ \\
\hline ICU admission (\%) & $6.67 \pm 6.67$ & $49.25 \pm 6.15$ & $* 0.002$ \\
\hline $\begin{array}{l}\text { The presence of systemic } \\
\text { infection (\%) }\end{array}$ & $13.33 \pm 9.09$ & $28.36 \pm 5.55$ & 0.233 \\
\hline $\begin{array}{l}\text { The presence of surgical } \\
\text { site infection (\%) }\end{array}$ & $13.33 \pm 9.09$ & $44.78 \pm 6.12$ & ${ }^{* *} 0.024$ \\
\hline Length of hospital stay (days) & $8.33 \pm 1.44$ & $10.04 \pm 0.86$ & 0.380 \\
\hline Postoperative AGR & $1.36 \pm 0.09$ & $1.31 \pm 0.04$ & 0.554 \\
\hline Postoperative LMR & $1.56 \pm 0.19$ & $1.56 \pm 0.13$ & 0.999 \\
\hline
\end{tabular}

'Student + test; SEM: Standard Error of Mean; NRS: Nutritional Risc Score; AGR: Albumin-globulin ratio; LMR: Lymphocyte-monocyte ratio; * very significant

TABLE 5. Data related to the comparison of two assessment tests in patients with malnutrition risk

\begin{tabular}{|c|c|c|c|}
\hline Variables & $\begin{array}{c}17<\text { MNA } \\
(n=36)\end{array}$ & $\begin{array}{l}\text { NRS-2002 } \geq 3 \\
\quad(n=67)\end{array}$ & $\mathrm{p}$ \\
\hline ICU admission (\%)' & $77.78 \pm 7.03$ & $49.25 \pm 6.15$ & $0.005^{*}$ \\
\hline $\begin{array}{l}\text { The presence of systemic } \\
\text { infection }(\%)^{1}\end{array}$ & $52.78 \pm 8.44$ & $28.36 \pm 5.55$ & 0.014 \\
\hline $\begin{array}{l}\text { The presence of surgical site } \\
\text { infection }(\%)^{\prime}\end{array}$ & $63.89 \pm 8.12$ & $44.78 \pm 6.12$ & 0.065 \\
\hline Length of hospital stay (days) ${ }^{2}$ & $12.89 \pm 1.48$ & $10.04 \pm 0.86$ & 0.078 \\
\hline Postoperative AGR ${ }^{2}$ & $1.26 \pm 0.05$ & $1.31 \pm 0.04$ & 0.715 \\
\hline Postoperative LMR² & $1.75 \pm 0.19$ & $1.56 \pm 0.13$ & 0.398 \\
\hline
\end{tabular}

Comparing the two screening tools, the incidence of ICU admission was significantly higher in patients with MNA>17 (Table 5), and MNA was a good predictor for ICU admission and the development of systemic infection (Table 6).

\section{DISCUSSION}

Elderly patients often suffer from malnutrition, which is a condition that is usually underestimated in surgical patients. However, the nutritional status is a main factor for the postoperative process. Our study indicated that patients with MNA $<17$ and NRS-2002 $\geq 3$ have significantly higher ICU admission rates and incidence of infection. When comparing the two screening tools, MNA has a better predictive value than NRS-2002. Regarding biochemical markers, LMR showed a significant decline after surgery, but this parameter has no correlation with the screening tools and postoperative outcome.

It is essential to assess the uniqueness of an elderly patient in order to achieve a successful perioperative management. The nutritional status has a paramount importance in the surgical risk stratification and the risk-modifying interventions that help to predict the surgical outcome. Malignancy is often associated with poor food intake. A prospective cohort study concerning elderly patients suffering from periampullary neoplasm indicated that $87 \%$ of patients were classified into the at-risk-of malnutrition or malnourished group by using the MNA screening tool. These patients showed a higher overall surgical morbidity (I7).

The prevalence of malnutrition in older patients with hip fracture is higher than in older adults. This is due to the fact that there is an increased need for calories secondary to the systemic inflammatory response, poor nutrition due to pain and decrease in mobility. In a review evaluating the effect of malnutrition and nutritional treatment on outcomes and mortality in elderly patients with a hip fracture, it was stated that malnutrition increases mortality (30\% within I year and up to $40 \%$ within 3 years.), affects functional recovery after the fracture, and increases health expenditures $(18,19)$.

Helminen et al. (20) stated in their study that they evaluated the prognosis of 594 elderly patients with hip fracture according to MNA-SF, MNA-LF, and serum albumin levels, and found that all of these tests were a strong indicator in determining short- and long-term mortality.

In our study, MNA-LF and NRS-2002 tests were used. MNA-LF was a good predictor for ICU admission and the development of systemic infection. In our study, no difference was found between preoperative and postoperative AGR. However, the LMR decreased in the postoperative period.

Norman et al. (2I) found that pressure sores and infections were associated with malnutrition. Our results are consistent with the work by Norman et al. Surgical site infection rate was higher in patients with NRS-2002 $\geq 3$ than in the group with NRS-2002 <3. In patients with MNA < I7, both systemic and surgical site infection rates were high. Gurnieiro et al. (22) established that MNA-LF is suitable for predicting mortality. In our study, the incidence of ICU admission was significantly higher in patients with malnutrition according to the two nutritional assessment tests used (MNA-LF and NRS-2002). 


\begin{tabular}{|c|c|c|c|c|c|c|}
\hline & AUC & $95 \% \mathrm{Cl}$ & Sensitivity (\%) & Specivity & Cut-off & $p$ \\
\hline \multicolumn{7}{|l|}{ MNA-LF } \\
\hline The presence of systemic infection & 0.722 & $0.612-0.815$ & 90.4 & 49.1 & 20.5 & $0.0004^{*}$ \\
\hline The presence of surgical site infection & 0.600 & $0.486-0.707$ & 37.5 & 84.0 & 13.5 & 0.139 \\
\hline ICU admission & 0.561 & $0.447-0.670$ & 47.0 & 64.5 & 3 & 0.329 \\
\hline The presence of systemic infection & 0.602 & $0.488-0.709$ & 33.3 & 83.6 & 4 & 0.157 \\
\hline The presence of surgical site infection & 0.532 & $0.418-0.643$ & 25.0 & 82.0 & 4 & 0.622 \\
\hline
\end{tabular}

JunDe et al. (23) compared MNA-SF, NRS-2002, biochemical markers among elderly patients and reported that MNA-SF may be a favorable test for nutritional analysis. Myoung-Ha et al. (24) compared five nutrition tests (MNA-LF, MNA-SF, GNRI, MUST, and NRS-2002) and reported that MUST is the best test for nutritional analysis. Koren-Hakim et al. (25) in their studies comparing the MNA-SF, NRS-2002, and MUST tests, found that all tests were performed well, although they reported that MNA-SF predicted readmissions and mortality better. In our study, when the two screening tests (MNA-LF and NRS-2002) were compared, the incidence of ICU admission was significantly higher in MNA-LF.

In a study where the nutritional status of 246 patients undergoing pancreotoduodenectomy was evaluated with the MNA test and biochemical markers (albumin, prealbumin, and transferrin), it was reported that malnutrition was related to poor postoperative outcomes (26).

In a retrospective, single-center study performed by Inove et al. (27) in elderly patients with a hip fracture, who underwent MNA-SF, NRS-2002, MUST, and the Geriatric nutritional risk index (GNRI) tests prior to surgery, MNA-SF was found to be an optimal test for nutritional screening.

\section{Limitations}

We acknowledge various limitations in our study. If a patient did not know his/ her height, the investigator estimated the height value.

Our study was conducted in a single center. A multicenter study will be needed to disseminate our results to a larger patient population.

In conclusion, consequently, the nutritional status is a topic that is often overlooked in preoperative evaluations. However, measurements with easy-to-perform tests will provide guidance in terms of identifying potential perioperative risks.

Nutritional risk screening tools can indicate the negative consequences of hospitalized patients.

MNA is a good predictor for ICU admission and the development of systemic infection.
Ethics Committee Approval: Ethics committee approval was received for this study from the ethics committee of Kartal Dr. Lütfi Kırdar Training and Research Hospital Clinical Research ethics committee (2018/514/144/3).

Informed Consent: Written informed consent was obtained from patients who participated in this study

Peer-review: Externally peer-reviewed.

Author contributions: Concept - Ö.S.; Design - Ö.S.; Supervision - B.C..; Resource - Ö.S., B.C.; Materials - Ö.S., B.C.; Data Collection and/or Processing - Ö.S.; Analysis and/or Interpretation - Ö.S., B.C.; Literature Search - Ö.S., B.C.; Writing - Ö.S.; Critical Reviews - B.C.

Conflict of Interest: Authors have no conflicts of interest to declare.

Financial Disclosure: The authors declared that this study has received no financial support.

\section{REFERENCES}

I https://www.who.int/news-room/fact-sheets/detail/ageingand-health

2. Evans C. Malnutrition in the Elderly: A multifactorial Failure to Thrive. Perm J 2005; 9(3): 38-4I. [Crossref]

3. Klestil T, Röder C, Stotter C, Winkler B, Nehrer S, Lutz M, et al. Impact of timing of surgery in elderly hip fracture patients: a systematic review and meta-analysis. Sci Rep 2018; 8(I): 13933. [Crossref]

4. Malafarina $\vee$, Reginster JY, Cabrerizo S, Bruyere O, Kanis JA, Martinez JA, et al. Nutritional Status and Nutritional Treatment Are Related to Outcomes and Mortality in Older Adults with Hip Fracture. Nutrients 2018; 10(5): 555. [Crossref]

5. Zhang, X, Tang T, Pang L, Sharma SV, Li R, Nyitray AG, et al. Malnutrition and overall survival in older adults with cancer: A systematic review and meta-analysis. J Geriatr Oncol 2019; 10(6): 874 - 83. [Crossref]

6. Correia MI, Waitzberg DL. The impact of malnutrition on morbidity, mortality, length of hospital stay and costs evaluated through a multivariate model analysis. Clin Nutr 2003; 22(3): 2359. [Crossref]

7. Nutrition Module: 5. Nutritional Assessment. https://www.open. edu/openlearncreate/mod/oucontent/view.php?id=318反printable=I. (Access date:03.01.2020)

8. Yürüyen $M$, Yavuzer $H$, Yavuzer $S$, Cengiz M, Demirdağ F, Kara Z, et al. Comparison of nutritional risk screening tools for predicting sarcopenia in hospitalized patients. Turk J Med Sci 2017; 47: 1362-9. [Crossref]

9. Kondrup J, Allison SP, Elia M, Vellas B, Plauth M. ESPEN guidelines for nutrition screening 2002. Clin Nutr 2003; 22(4): 4I5-21. [Crossref] 
10. Cereda E. Mini Nutritional Assessment. Curr Opin Clin Nutr Metab Care 2012; 15(I): 29-4I. [Crossref]

II. Abellan van Kan G, Rolland Y, Bergman H, Morley JE, Kritchevsky $\mathrm{SB}$, Vellas B. Frailty assessment of older people in clinical practice expert opinion of a geriatric advisory panel. J Nutr Health Aging 2008; I2(I): 29-37. [Crossref]

12. Keller U. Nutritional Laboratory Markers in Malnutrition. J Clin Med 2019; 8(6): 775. [Crossref]

13. Zhang Y, Wang L, Lin S, Wang R. Preoperative albumin-to-globulin ratio as a significant prognostic indicator in urologic cancers: a meta-analysis. Cancer Manag Res 2018; 10: 4695-708. [Crossref]

14. Vellas B, Villars H, Abellan G, Soto ME, Rolland Y, Guigoz Y, et al. Overview of the MNA-its history and challenges. J Nutr Health Aging 2006; 10(6): 456-63.

15. Kondrup J, Allison SP, Elia M, Vellas B, Plauth M, Educational and Clinical Practice Committee, European Society of Parenteral and Enteral Nutrition (ESPEN). ESPEN guidelines for nutrition screening 2002. Clin Nutr 2003; 22(4): 4I5-21. [Crossref]

16. Buckley RG, Stehman CR, Dos Santos FL, Riffenburgh RH, Swenson A, Mios N, et al. Bedside method to estimate actual body weight in the Emergency Department. J Emerg Med 2012; 42(I): 100-4. [Crossref]

17. Kim E, Lee DH, Jang JY. Effects of preoperative malnutrition on Postoperative Surgical Outcomes and Quality of Life of Elderly Patients with Periampullary Neoplasms: A-Single Center Prospective Cohort Study. Gut Liver 2019; 13(6): 690-7. [Crossref]

18. Watterson C, Fraser A, Banks M, Isenring E, Miller M, Silvester C, et al. Evidence based practice guidelines for the nutritional management of malnutrition in adult patients across the continuum of care. Nutr Diet 2009; 66(3): I-34. [Crossref]

19. Malafarina V, Reginster JY, Cabrerizo S, Bruyere O, Kanis JA, Martinez JA, et al. Nutritional Status and Nutritional Treatment Are Re- lated to Outcomes and Mortality in Older Adults with Hip Fracture. Nutrients 2018; 10(5): I-26. [Crossref]

20. Helminen H, Luukkaala T, Saarnio J, Nuotio M. Comparison of the Mini-Nutritional Assessment short and long form and serum albu$\mathrm{min}$ as prognostic indicators of hip fracture outcomes. Injury 2017; 48(4): 903-8. [Crossref]

21. Norman K, Pichard C, Lochs H, Pirlich M. Prognostic impact of disease-related malnutrition. Clin Nutr 2008; 27(I): 5-15. [Crossref]

22. Gumieiro DN, Rafacho BP, Goncalves AF, Tanni SE, Azevedo PS, Sakane DT, et al. Mini Nutritional Assessment predicts gait status and mortality 6 months after hip fracture. Br J Nutr 2013; 109(9): 16576l. [Crossref]

23. JunDe Z, Miao W, HaiKuan W, Qiang C. Comparison of two nutrition assessment tools in surgical elderly inpatients in Northern China. Nutr J 2015; 14: 68. [Crossref]

24. Myong-Ha B, Young-Ran H. Evaluation of the efficacy of nutritional screening tools to predict malnutrition in the elderly at a geriatric care hospital. Nutr Res Pract 2015; 9(6): 637-43. [Crossref]

25. Koren-Hakim T, Weiss A, Hershkovitz A, Olzrateni I, Anbar R, Gross Nevo RF, et al. Comparing the adequacy of the MNA-SF, NRS2002 and MUST nutritional tools in assessing malnutrition in hip fracture operated elderly patients. Clin Nutr 2016; 35(5): 1053-58. [Crossref]

26. Kim E, Kang JS, Han Y, Kim H, Kwon W, Kim JR, et al. Influence of preoperative nutritional status on clinical outcomes after pancreatoduodenectomy. HFB (Oxford) 2018; 20 (II): 105I-6I. [Crossref]

27. Inove T, Misu S, Tanaka T, Kakehi T, Ono R. Acute phase nutritional screening tool associated with functional outcomes of hip fracture patients: A longitudinal study to compare MNA-SF, MUST, NRS2002 and GNRI. Clin Nutr 2019; 38(I): 220-6. [Crossref] 